\title{
O MODELO FÍSICO AJUSTÁVEL PARA A IDENTIFICAÇÃO DAS PRIORIDADES DOS USUÁRIOS DE HABITAÇÃO DE INTERESSE SOCIAL
}

\section{THE ADJUSTABLE PHYSICAL MODEL FOR IDENTIFYING PRIORITIES OF SOCIAL HOUSING USERS}

\author{
Marcela Gomes de Albuqurque Zalite 1 \\ Centro Universitário Unicesumar, Maringá, Paraná, Brasil, marcela_maz@hotmail.com \\ César Imai 2 \\ Universidade Estadual de Londrina, Londrina, Paraná, Brasil, cimai@uel.br
}

\section{Resumo}

No Brasil, a oferta de projetos padronizados e com dimensões mínimas para as habitações de interesse social demanda maior atenção e aponta a necessidade do desenvolvimento de projetos mais eficientes considerando as transformações que ocorrem nos costumes e nos perfis familiares. A participação dos usuários no processo do projeto pode contribuir na qualidade do ambiente construído ao permitir o entendimento das necessidades desses usuários, pois este processo é baseado no aprimoramento da comunicação entre leigos e profissionais. Nesse contexto, o objetivo deste trabalho foi realizar uma simulação com o uso do modelo tridimensional físico ajustável como modo de investigar as prioridades e desejos dos usuários das habitações de interesse social. O modelo permite ajustes e alterações rápidas nas posições de paredes e aberturas, proporcionando uma leitura clara de diferentes opções de projeto. Além da simulação, o método de pesquisa também incluiu um questionário e a técnica de preferência declarada com modelos digitais. Foi possível observar que essas ferramentas auxiliaram na coleta das informações, permitindo que os entrevistados expressassem suas prioridades e as motivações das suas escolhas. A simulação com modelo físico ajustável demonstrou eficácia na comunicação do projeto, para pessoas leigas ao aproximar os envolvidos das decisões sobre o projeto da moradia e auxiliar os futuros moradores a fazerem escolhas mais conscientes.

Palavras-chave: Simulação, Modelo tridimensional físico, Habitação de Interesse Social

\begin{abstract}
In Brazil, the offer of standardized projects with minimum dimensions for social interest housings demands greater attention and indicates the need to develop more efficient projects considering the changes that occur in customs and family profiles. The participation of users in the project process can contribute to the quality of the built setting by allowing the understanding of the needs of these users, in a process based on the improvement of communication between layman and professionals. In this context, the objective of this work was to perform a simulation with the use of an adjustable physical three-dimensional model as a way to investigate the priorities and desires of the users of social housing. The model allows quick adjustments and changes in the positions of walls and openings, providing a clear reading of different design options. Besides the simulation, the research method also includes a questionnaire and the declared preference technique with digital models. It was possible to observe that these tools helped to collect the information, allowing the interviewees to express their priorities and the motivations of their choices. The simulation with the adjustable physical model demonstrated the effectiveness of the project's communication to layman, brings the decision-makers closer to the housing project and helps future residents to make more conscious choices.
\end{abstract}

Keywords: Simulation, models, Social housing

How to cite this article:

ZALITE, Marcela Gomes de Albuquerque; IMAI, César. O modelo físico ajustável para a identificação das prioridades dos usuários de habitação de interesse social. PARC Pesquisa em Arquitetura e Construção, Campinas, SP, v. 8, n. 1, p. 20-31, mar. 2017. ISSN 1980-6809. Disponível em: <https://periodicos.sbu.unicamp.br/ojs/index.php/parc/article/view/8649670>. Acesso em: 09 set. 2017. doi:http://dx.doi.org/10.20396/parc.v8i1.8649670. 


\section{Introdução}

A discussão sobre a qualidade das habitações de interesse social no Brasil ainda é um tema relevante, considerando que o modelo de produção pública ainda não resolveu as demandas atuais. A introdução de novas tecnologias e ideias se apresenta como um desafio diante das limitações financeiras. Como consequência dessa problemática resulta a padronização de projetos com dimensões mínimas, a qual surge como recurso para alta produção e baixo custo na construção das edificações.

Nesse cenário, é possível observar que os projetos de Habitação de Interesse Social não são capazes de agregar os aspectos da grande diversidade das formações familiares que tem surgido na sociedade moderna, bem como não consideram a personalidade e identidade dos moradores e de cada família (VILLA et al., 2013).

A consideração de aspectos subjetivos influencia sobremaneira a satisfação das pessoas com sua moradia (ELALI, 2010). Como forma de entender e agregar esses aspectos nas habitações, os processos de projeto devem ser guiados com a participação dos usuários e com o uso de meios de comunicação que facilitem a integração dos usuários.

Mesmo diante da evolução das representações virtuais na arquitetura, a comunicação por meio das representações gráficas e por modelos físicos não foi minimizada ou substituída. O impacto da nova era digital, com uso de programas avançados na área de computação, foi significativo e contribui para desenvolvimento de projetos cada vez mais complexos. Ainda assim, os modelos físicos tridimensionais continuam sendo um instrumento útil, por sua capacidade de proporcionar uma percepção mais concreta e direta com o usuário e pelo aspecto lúdico que possui certo poder de atração e aguça o interesse das pessoas. Essa ferramenta acompanhou as transformações e desenvolvimentos tecnológicos, sendo possível a elaboração por meio de programas digitais e produção com auxílio de impressoras 3D (CELANI et al, 2007).

$\mathrm{O}$ presente artigo expõe uma pesquisa voltada para a questão da descoberta das preferências que os usuários de Habitação de Interesse Social declaram por meio de simulação com modelo físico tridimensional, considerando as restrições financeiras. Seu foco se dá na identificação do comportamento e efetividade do modelo tridimensional físico para coleta de informações junto às pessoas leigas, que moram em HIS, na identificação das preferências declaradas dos usuários, diante de restrições dimensionais, das diversidades e homogeneidades entre essas famílias e das potencialidades no uso da ferramenta de simulação com uso de modelo físico.
A estratégia se justifica por ampliar o conhecimento de técnicas que oportunizem a participação efetiva dos usuários no processo de projeto e do desenvolvimento das possibilidades de comunicação entre projetistas e pessoas envolvidas, de forma que seja possível compreender as prioridades apontadas pelos moradores de HIS.

O conceito de "simulação", neste estudo, indica a possibilidade de apresentar de forma ágil, diretamente com o público alvo, variados tipos de plantas baixas e situações de leiaute. Dessa forma, o termo "modelo tridimensional físico" trata-se de um objeto que se difere da maquete tradicional por não ser uma ferramenta de representação estática, mas sim um protótipo com flexibilidade e dinamismo. Ele busca permitir alterações significativas nos projetos modificando dimensões, aberturas e leiaute dos ambientes em tempo real pelos usuários leigos em discussões com técnicos.

\section{Fundamentação teórica}

A qualidade das edificações pode ser medida com critérios classificados de acordo com diferentes aspectos ou estágios da edificação, que implica o período de planejamento, de comercialização e após o uso. Segundo Ornstein, Fabrício e Melhado (2010) o ciclo de vida de uma obra envolve diferentes pessoas e interesses, abrange naturezas econômicas, sociais e culturais. Para Woordt e Wegen (2013) o conceito de qualidade está voltado para o atendimento das necessidades dos usuários, e ampliando o conceito, a Associação Norte-Americana da Qualidade (ASQ) aponta qualidade nos produtos que respondem às expectativas declaradas e também implícitas dos clientes (ELALI, 2010).

Aspectos dimensionais, estéticos e de funcionalidade se destacam como elementos de forte influência na satisfação dos usuários com sua moradia. Pesquisas de avaliação pósocupação e de campo realizadas por (VILLA et al., 2013; SILVA; SILVA, 2012) demonstram que existe uma demanda por habitações de dimensões maiores que as oferecidas hoje pelos programas sociais. Palermo (2013) inclusive aponta que os espaços mínimos dessas habitações acabam por prejudicar a adequação do mobiliário, bem como a circulação entre eles. $\mathrm{O}$ planejamento dos ambientes ainda deve se voltar aos tipos de atividades realizadas nos ambientes e aos espaços necessários para uso do mobiliário e equipamentos.

Em relação aos fatores estéticos, a satisfação do usuário por sua moradia se inclina a elementos de ordem social, cultural, ou seja, de ordem psicológica (REIS; LAY, 2013). A aparência dos espaços pode trazer sentimentos de orgulho ou vergonha, por isso, à medida que o usuário se identifica com sua moradia, ele cria um laço afetivo, o que leva à satisfação e realização com o lugar. De certa forma, o local o representa. 
Sobre o ponto de vista da funcionalidade, Woordt e Wegen (2013) defendem que a edificação cumpra com a função para que foi designada, proporcione clima adequado ao uso, tenha valor simbólico e financeiro e qualidade funcional. Contudo, ocorrem questões subjetivas, chamada de funcionalidade afetiva, capaz de proporcionar sensações "agradáveis". Estas necessidades podem ser detectadas a partir do entendimento das mudanças dos hábitos e costumes das pessoas ou de uma região, por exemplo (BARROS; COUTO, 2013). O modo como pessoas utilizam a moradia se transforma continuamente, assim, ainda deve se levar em consideração que os hábitos e preferências de uma determinada população poderão sofrer alterações.

Como fator de complexidade, na busca de um projeto que ofereça os anseios dos usuários, encontram-se as questões subjetivas. Segundo Kowaltowski et al (2006), deve-se direcionar um olhar atento para alguns resultados de pesquisas voltadas à HIS, pois muitos apontam para usuários satisfeitos com moradias precárias. O que poderia ser um indicador de qualidade no projeto da habitação social fica condicionado a uma interpretação mais profunda. A satisfação dos usuários pode estar relacionada com a alteração de status, quando ele passa a ser o proprietário da moradia ou quando ele alcança uma moradia melhor que a anterior. $\mathrm{O}$ indivíduo também pode se sentir satisfeito com uma moradia de baixa qualidade técnica ao constatar que não tem possiblidade futura de obter uma habitação melhor que a atual, nesse caso o conformismo é ponto positivo para reverter uma situação de frustação (BLANK-FREITAS; AÑAÑA; SCHRAMM, 2013).

Outro fator relevante é que a sociedade tem vivido transformações muito rápidas e o mercado, atualmente, vem buscando alcançar a qualidade por meio de produtos mais personalizados. Os núcleos familiares se tornaram mais diversificados, abrindo espaço para famílias menores, como dink`s, (casais sem filhos), famílias monoparentais, pessoas que vivem sós (TRAMONTANO, 1997), entre outras.

Considerando as necessidades e desejos subjetivos dos usuários, sob o olhar dos princípios da psicologia ambiental pode-se ter um melhor entendimento das relações que o ser humano tem com o lugar por meio de seus princípios como a percepção, a cognição e o comportamento (GÜNTHER; ELALI; PINHEIRO, 2004; DEL RIO; DUARTE; RHEINGANTZ, 2002). Alguns dos aspectos que relacionam a satisfação residencial com a qualidade de vida são apresentados por Elali e Pinheiro (2013) podem ser considerados como essenciais na elaboração do projeto da habitação: a) Aspectos culturais: que se relacionam com o modo de vida do ser humano, o qual planeja e altera o espaço conforme suas necessidades;

b) Aspectos temporais: os quais ocorrem de forma linear (passado, presente e futuro) ou de forma cíclica (repetições de atividades diárias);

c) Aspectos afetivos: que se referem ao apego que a pessoa possui pela moradia, os vínculos criados com determinados espaços;

d) Aspectos de apropriação: que se formam a partir do espaço como território, onde ocorre o sentimento de pertencimento, bem como a personalização do local e;

e) Aspectos sócios espaciais: maneira em que as pessoas percebem ou experimentam os espaços em que vivem e circulam, sentimento de privacidade, aglomeração e espaço pessoal, Elali e Pinheiro (2013).

Salgado (2010) aponta que, além de atender aos requisitos técnicos e funcionais, também devem ser levados em consideração os anseios individuais das pessoas. Muitas vezes as necessidades verbalizadas pelos usuários podem ser consideradas como óbvias, como por exemplo, a necessidade de que a casa tenha um banheiro. Em outros casos, os usuários esperam uma característica específica da moradia, mesmo que não a solicitem. E, por fim, podem ocorrer necessidades inesperadas, quando o usuário só percebe a importância de determinada questão a partir do momento em que entra em contato com essa característica, depois que o projeto ou a edificação já estejam concretizados.

\section{Simulação}

Os modelos tridimensionais foram muito utilizados no decorrer da história como forma de apresentação e comunicação. Eles explicitam de maneira mais compreensível, comparando as peças gráficas bidimensionais, as ideias dos projetistas para outros envolvidos no processo do projeto, inclusive auxiliando o criador a refletir sobre suas próprias ideias para obtenção de novas soluções (SCHON, 2000; FLORIO; TAGLIARI, 2011).

Em comparação com o computador, os modelos apresentam a vantagem de permitir a manipulação física que permitiria um contato mais direto (PALLASMAA, 2011). Nesse sentido, o sujeito que passa da atitude de observador para participante amplia o conhecimento sobre os objetos por meio do tato e da própria manipulação.

Pupo e Celani (2011) consideram também que as maquetes físicas são mais eficientes que as maquetes digitais, pois auxiliam a verificação de problemas e soluções projetuais. Imai (2009) ainda aponta que os modelos oferecem a possibilidade de maior entendimento do projeto às pessoas 
leigas, podendo facilitar a tomada de decisão e contribuir de maneira mais consciente para apresentar melhorias no resultado do projeto

A exposição de ideias não exige necessariamente de uma grande elaboração nos acabamentos do modelo, pois a abstração e a simples apresentação dos volumes pode oferecer uma comunicação efetiva e rápida (ROZESTRATEN, 2006).

Essas qualidades dos modelos físicos, citadas acima, funcionam como impulso para o diálogo e a participação dos usuários no processo do projeto. Segundo Azuma (2016), a participação do usuário e do projetista no projeto ocorre em patamares diferentes com barreiras de comunicação e escala de poderes, gerando uma participação parcial onde o usuário pode expor suas ideias. Contudo, as decisões definitivas serão tomadas por quem possui maior conhecimento, presumindo-se o projetista. $\mathrm{O}$ autor aponta a participação como um ato coletivo onde cada um possui o poder de aplicar sua habilidade específica.

A utilização de modelo tridimensional físico nessa pesquisa tem o foco de promover a participação dos usuários criando um meio de interação, onde as partes podem praticar uma comunicação com entendimento mais completo.

O processo de avaliação de um projeto acaba ocorrendo de maneira invariável por seus usuários após a ocupação. Segundo BECHTEL (1989), a avaliação pós-ocupação e a avaliação pré-projeto são métodos complementares, enquanto um oferece as soluções para futuros projetos, o outro testa essas soluções para apontá-las como eficientes.

As avaliações pré-projeto melhoram a qualidade do projeto e do programa de necessidades, elas têm capacidade de produzir um banco de dados que poderá apontar soluções para conflitos a tempo e proporcionar alterações com facilidade e baixo custo. Imai (2010) aponta que assim é possível conhecer as necessidades e exigências dos futuros usuários.

Nessa pesquisa foi utilizada a simulação com o modelo tridimensional físico. Este instrumento permite a apresentação do projeto às pessoas leigas de forma rápida, realística (SANOFF, 1991; WANG; GROAT, 2002) Ela cria um meio de diálogo onde seja possível identificar os desejos dos usuários, de forma a avaliar algumas tentativas de soluções e alterações projetuais (SPRECKELMEYER, 1987). Os autores Bosselmann e Craik (1990) citam como vantagens dessa estratégia, a capacidade de ampliar a participação das pessoas e as tomadas de decisões antes da construção da edificação.
As simulações realizadas por meio de modelos físicos e virtuais oferecem a possibilidade de testar grande variedade de cores, texturas e iluminação, além das estruturas e volumes. Para Celani et al. (2007) o uso do $\mathrm{CAD}$, assim como os recursos de rendering auxiliam a transformar a transmitir mais realismo aos modelos virtuais, inclusive apontando pontos de conflito no projeto. Estes aspectos citados, além de outros como a facilidade e tempo de confecção são algumas das vantagens que os modelos virtuais têm em relação aos modelos físicos.

Entretanto, eles não conseguem substituir os modelos físicos em outras questões como, por exemplo, a manipulação e a compreensão da totalidade. $\mathrm{O}$ uso desses instrumentos se complementa no momento da comunicação e apresentação das ideias.

Os modelos físicos permitem observação de questões subjetivas tanto para o projetista como para os outros envolvidos no projeto, e, ao buscar a reprodução do mundo real, tende a levar o expectador para dentro daquele espaço (PINA; BORGES FILHO; MARANGONI, 2011, p. 114).

A pesquisa apresentada nesse texto busca oportunizar a elaboração de um leiaute pelos participantes leigos, por meio de uma simulação utilizando um modelo físico ajustável, de forma que possam compreender e perceber melhor os espaços manipulados por elas.

\section{Métodos de pesquisa}

Este trabalho apresenta a utilização de um modelo tridimensional físico ajustável utilizado como meio de identificar as preferências de usuários de habitação de interesse social. A coleta de dados se completa com abordagens múltiplas, chamada de "multimétodos" (GÜNTHER; ELALI; PINHEIRO, 2011), utilizando a simulação, a preferência declarada, a entrevista e o questionário junto a moradores de habitação de interesse social.

A coleta de informações se deu com base nos critérios da qualidade funcional propostos por Voordt e Wegen (2013), os quais incluem uma abordagem subjetiva. São eles:

- Flexibilidade: ajuste e adaptação do ambiente a uma situação específica. Capacidade de sofrer alterações e variações de dimensão, forma ou localização, com auxílio de operações de construção, ou ser multifuncional, polivalente ou neutro, quando pode se adequar a novas funções ou necessidades sem exigir operações de construção:

- Segurança: que se classifica em pública, psicológica ou ergonômica. 
- Orientação espacial: a qual observa as formas, a identidade, o uso de cores e a estética dos ambientes.

- Privacidade: controle da aproximação de outros à própria pessoa, podendo ser visual, auditiva e social; ao espaço pessoal, que é a área invisível em torno do indivíduo; e ao comportamento territorial, o qual demarca uma área como propriedade: os quais podem ser influenciados pelas características da edificação, como por exemplo, a vista da janela, a iluminação, o ruído, as cores, os materiais e o espaço para uso de mobiliários e equipamentos.

As simulações foram realizadas junto aos moradores de dois conjuntos habitacionais de apartamentos, localizados na cidade de Maringá. Esses usuários foram escolhidos para participar das simulações por terem a experiência de moradia e cotidiano em espaços reduzidos em apartamentos de cerca de 43,00 $\mathrm{m} 2$ que não podem sofrer modificações de ampliações em seus espaços interiores da unidade habitacional.

O projeto utilizado como referência para elaboração dos modelos apresentados na simulação foi escolhido após análise das habitações entregues com o Programa Minha Casa Minha Vida - PMCMV e no Programa de Aceleração do Crescimento - PAC, por meio da secretaria de Habitação de Maringá. As casas liberadas pelo programa habitacional do governo federal, para famílias de 0 a 3 salários mínimos que foram observadas, possuem de $36,36 \mathrm{~m}^{2}$ a $41,93 \mathrm{~m}^{2}$.

Foram realizadas 30 entrevistas no total, nos salões de festas dos condomínios. O procedimento da pesquisa foi planejado para adequação do tempo de duração da simulação e da ordem das atividades que seriam realizadas (Figura 1). A duração foi de trinta minutos, tempo calculado suficiente para coleta das informações sem cansar ou afastar os participantes.

Figura 1 - Procedimento da simulação

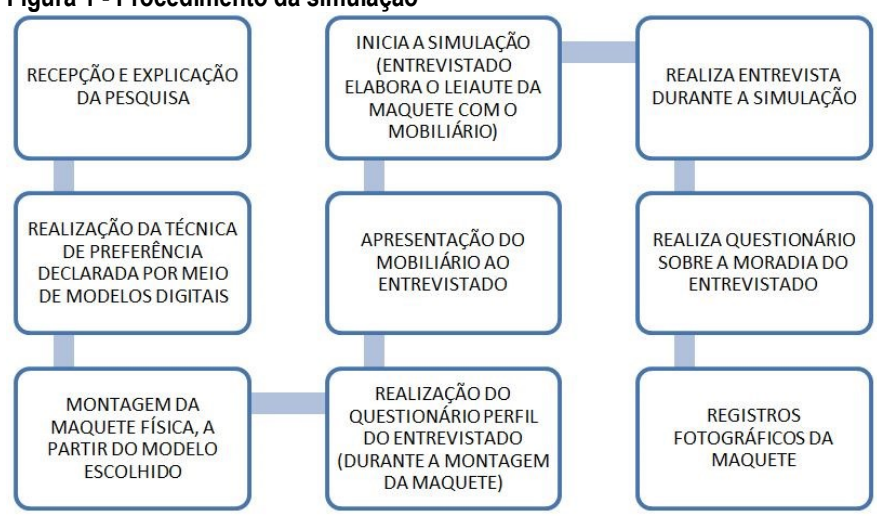

Fonte: Adaptado de Zalite (2016)

Na primeira etapa, por meio de modelos digitais (Figura 2), o participante selecionava um projeto de habitação entre quatorze alternativas diferentes, porém com dimensões similares, como casas com cozinha para frente ou cozinha para o fundo do terreno (Figura 3 e 4). Em seguida, o participante escolhia entre um o projeto básico ou projetos de casas com garagem, ou com área de serviço ou com suíte. E finalmente, escolhiam se preferiam um projeto de casa com frente recortada ou quadrada.

Figura 2 - Exemplos de projetos da moradia apresentados aos entrevistados em modelo digital.

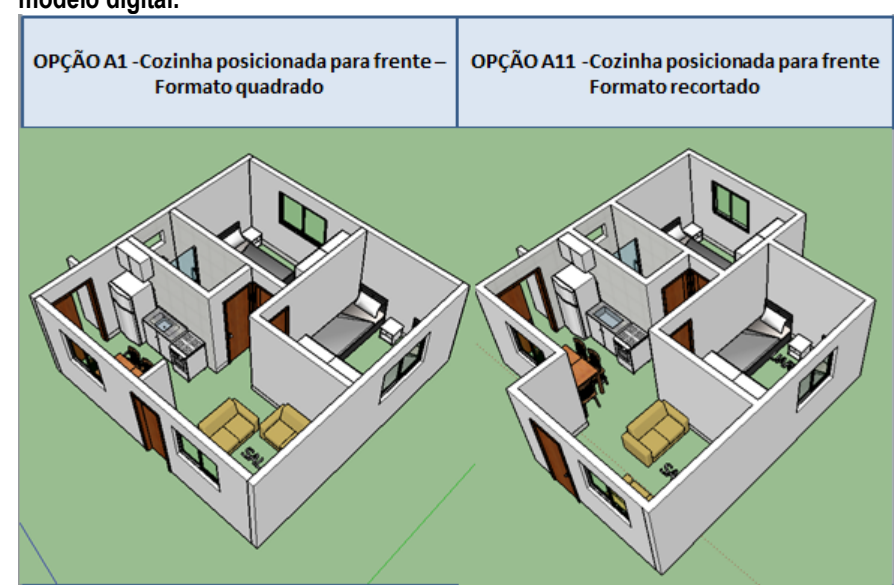

Fonte: Adaptado de Zalite (2016)

Em seguida, o pesquisador organizava a montagem do modelo físico com o projeto escolhido pelo entrevistado, etapa na qual o participante era convidado a elaborar um leiaute com utilização do mobiliário disponível. Durante este processo inicial foi aplicado um questionário para identificar informações básicas do entrevistado como suas características pessoais e familiares.

Figura 3 - Exemplos de projetos utilizados na entrevista (com cozinha para frente)
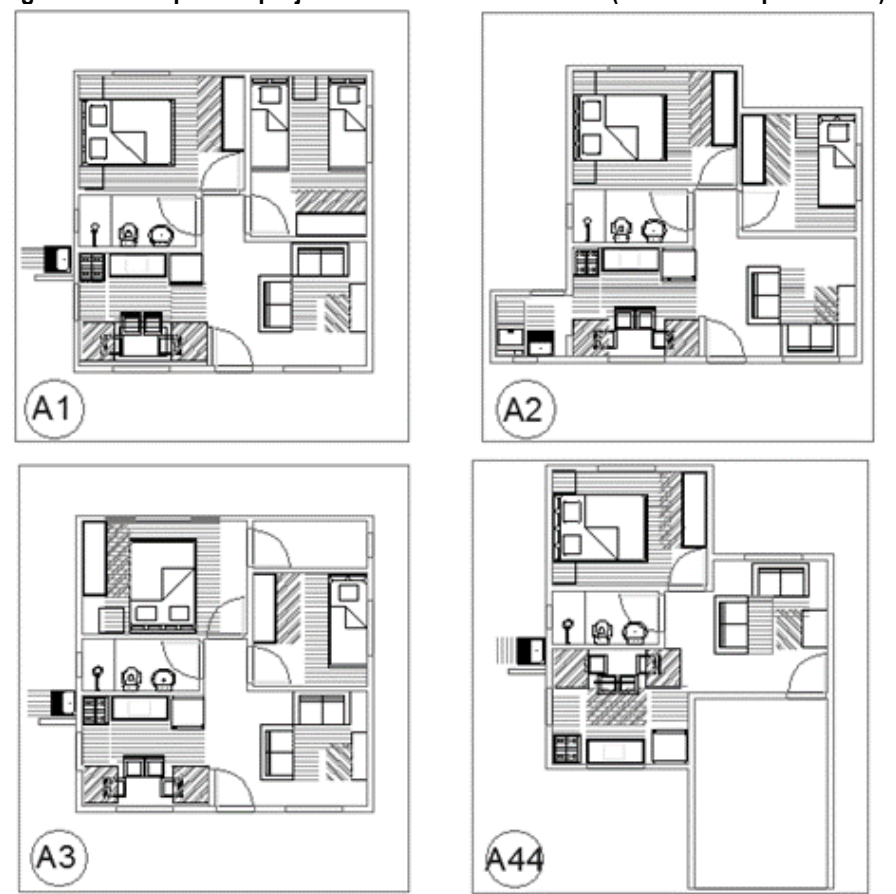

Fonte: Zalite (2016) 
Figura 4 - Exemplos de projetos utilizados na entrevista (com cozinha para os fundos)

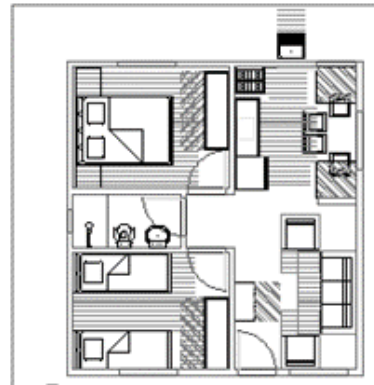

B1

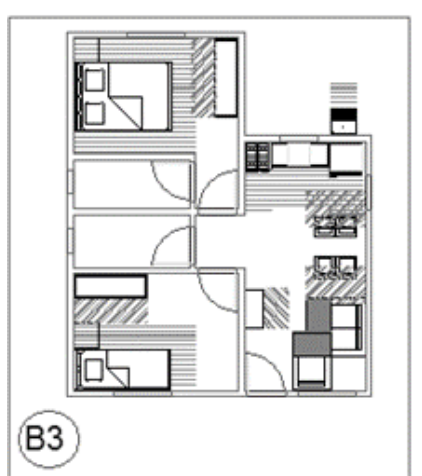

Fonte: Zalite (2016)

Posteriormente foram realizadas perguntas em forma de entrevista semiestruturada com objetivo de entender as preferências do participante. Foi questionado, por exemplo, se ele preferia cozinha integrada ou separada da sala; o motivo da escolha da localização das portas e janelas; se ele gostaria de ampliar algum ambiente com a condição de reduzir outro e como foi o seu entendimento em relação ao modelo físico e ao modelo digital. Também foi questionado sobre suas preferências na moradia atual; qual ambiente era o preferido para realizar as atividades do dia a dia; se a moradia atendia as necessidades no futuro; qual o nível de importância dado à possibilidade de alterar o leiaute e de poder utilizar um ambiente para atividades diferentes e se eventualmente incluiria algum ambiente diferente na moradia.

As características do modelo físico utilizado facilitava e agilizava a montagem de uma variedade de projetos diferentes. As paredes formadas em módulos eram retráteis, por isso, eram capazes de ajustar ambientes com dimensões variadas. Os módulos tinham formato em "L" de $2,4 \times 2,4 \mathrm{~m}, 0,9 \times 0,9 \mathrm{~m}, 0,9 \times 2,4 \mathrm{~m}$ e $0,9 \times 1,5 \mathrm{~m}$ podiam alcançar até quase o dobro dessa largura, possibilitando a montagem de uma infinidade de modelos a partir da combinação deles e a altura de $2,10 \mathrm{~m}$ facilitava a colocação das aberturas. A inclusão das aberturas também era simples e seu sistema possibilitava a alteração da localização das portas e janelas (Figura 5 e 6 ).

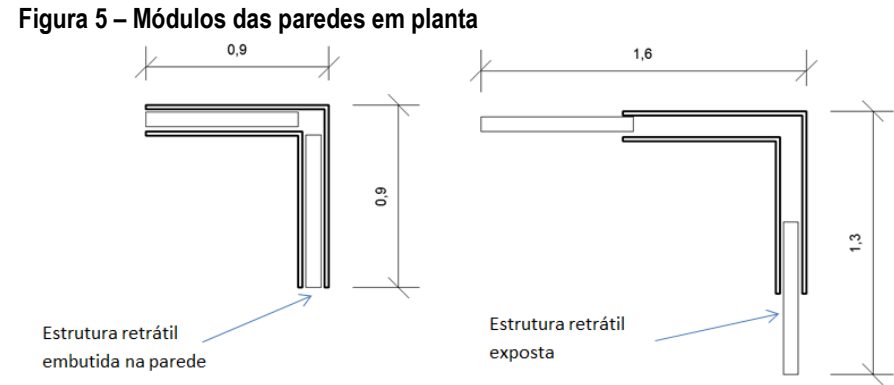

Fonte: Os autores

Figura 6 - Participante inserindo a porta na parede da maquete no momento da simulação

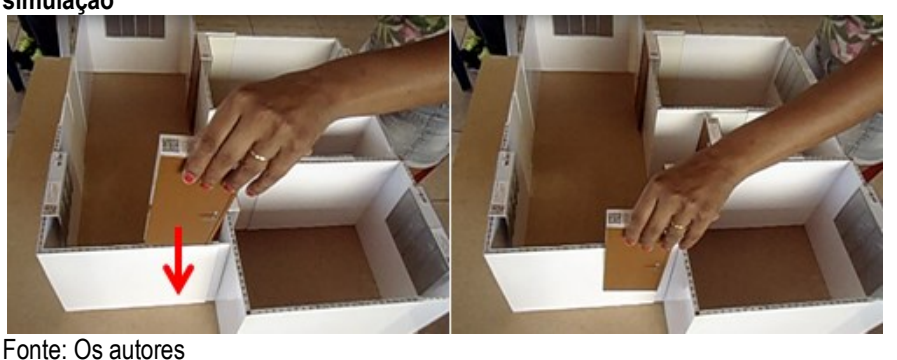

O modelo e o mobiliário foram executados na escala 1:10. Segundo Celani et al. (2009), a escala considerou a questão da facilidade de transporte, bem como a percepção das pessoas, de forma a ser suficientemente grande para visualização, mas sem dificultar o deslocamento da maquete (Figura7).

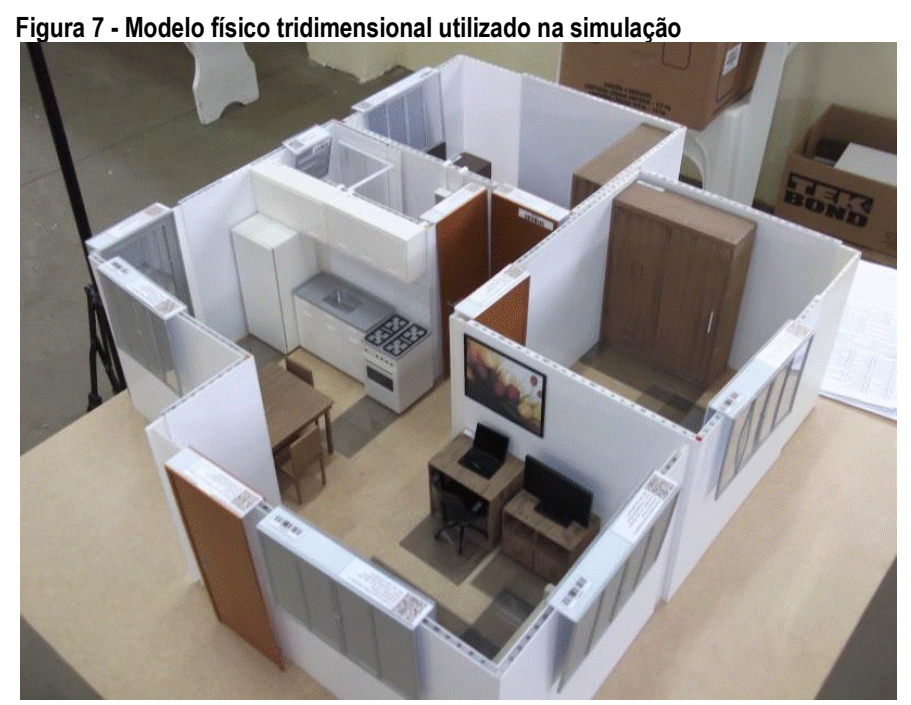

Fonte: Zalite (2016)

\section{Resultados}

Sobre a amostra resultante de participantes, as informações mais relevantes sobre o perfil socioeconômico foram que dos trinta entrevistados, vinte eram mães que moravam com filhos e/ou com netos, sem companheiros, além de que apenas dois homens aceitaram participar da pesquisa. 
Quanto à escolha dos projetos, o resultado foi muito diversificado, sendo indicados onze projetos, das quatorze possibilidades (Figura 8).

Figura 8 - Quanto à preferência nos tipos de projeto

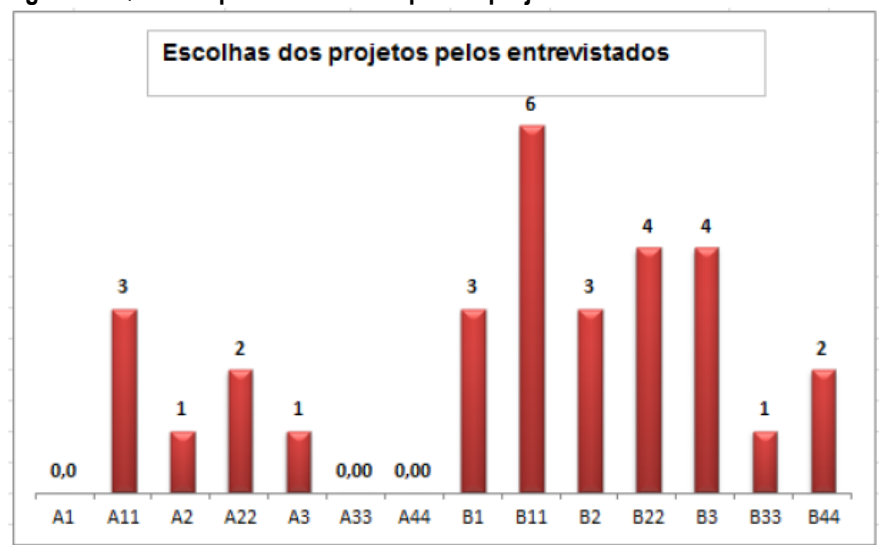

Fonte: Zalite (2016)

Alguns respondentes apontaram que a escolha do projeto não contemplou os ambientes preferidos, mas os que consideravam básicos, motivados pela restrição das dimensões, uma vez que se incluíssem espaços como suíte, área de serviço ou garagem, os outros ambientes da casa poderiam sofrer redução. Posteriormente eles poderiam escolher formas de ampliação.

Entre os projetos escolhidos, sem considerar a localização da cozinha ou formato da casa, onze pessoas preferiram o projeto padrão e dez apontaram o projeto com área de serviço. Nesse caso, é relevante ressaltar que o apartamento onde moram atualmente possui área de serviço com dimensão muito reduzida.

Os projetos com cozinha para os fundos foram escolhidos por vinte e três participantes. As justificativas mais comuns foram a necessidade de privacidade para $\mathrm{o}$ trabalho na cozinha e o acesso para área de serviço. Entre os que escolheram a cozinha para frente do terreno, as motivações indicaram a necessidade de visualização da rua, como forma de segurança ou lazer (Figura 9).

Figura 9 - Quanto à preferência da cozinha se posicionar para frente ou para o fundo do terreno quanto a incluir outros ambientes

\begin{tabular}{|c|c|c|}
\hline & TOTAL: 23 & \multirow{8}{*}{ 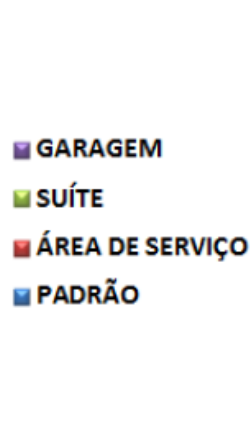 } \\
\hline & 2 & \\
\hline & 5 & \\
\hline & \multirow[t]{2}{*}{7} & \\
\hline TOTAL: 7 & & \\
\hline 1 & \multirow{3}{*}{9} & \\
\hline 3 & & \\
\hline 3 & & \\
\hline FRENTE & FUNDO & \\
\hline
\end{tabular}

Fonte: Zalite (2016)
Quanto ao formato das casas, o projeto com frente recortada foi preferido por dezoito entrevistados, contudo, os motivos foram variados, divergindo entre estética, percepção de espaço mais amplo, porém a maior parte respondeu que não sabia o porquê da escolha.

A preferência de separar a sala da cozinha confirmou pesquisas anteriores (ABIKO; ORNSTEIN, 2002), no entanto, quatorze pessoas escolheram ter a cozinha ligada à sala, de forma direta ou com uso de bancada ou mureta. As justificavas voltaram-se para a falta de espaço e a necessidade de adequar o mobiliário desejado. Tal preferência apresenta uma aceitação das cozinhas integradas com a sala (Figura 10).

Sob o aspecto do uso do modelo físico, é possível observar que a manipulação com inclusão de mobiliário colaborou para que a pessoa leiga pudesse compreender as dimensões dos ambientes, escolhendo a integração da cozinha com sala como alternativa de adequar as necessidades.

Figura 10 - Modelos elaborados pelos entrevistados com diferentes projetos para sala e cozinha

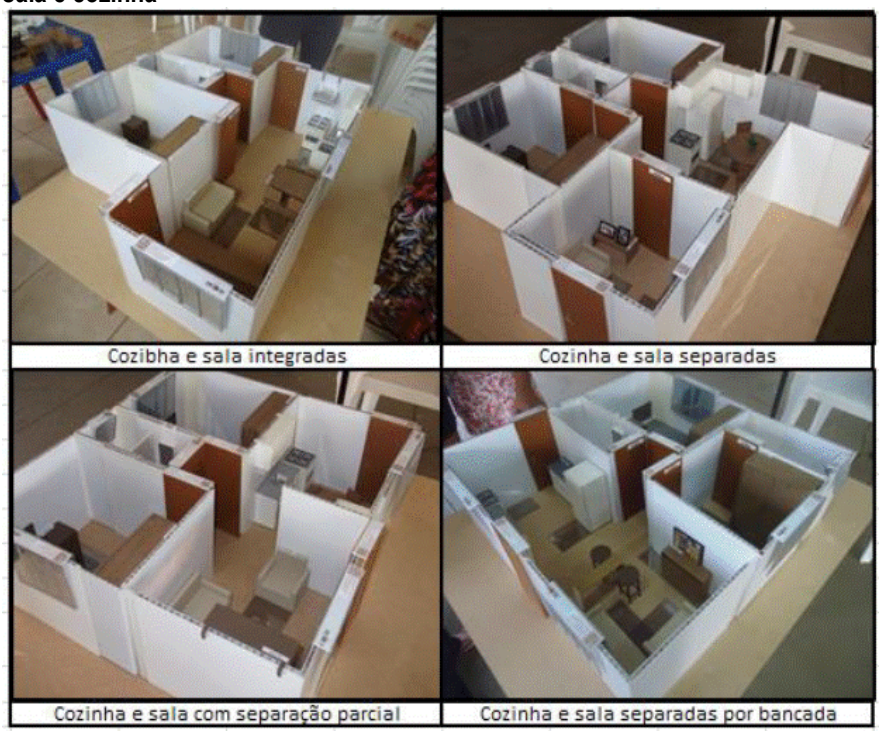

Fonte: Zalite (2016)

A dimensão da cozinha foi considerada pequena para a maioria dos participantes, assim, quinze deles desejavam ampliar esse ambiente. Destaca-se, nessa questão, que o desejo de possuir ambientes maiores não foi influenciado pelo número de pessoas na família, indicando que as preferências são subjetivas e não apontam uma razão única. Orientações anteriores, culturais, psicológicas, podem tornar complexa a tentativa de homogeneização de características familiares, o que torna difícil a utilização dessas características como base para elaboração de outros projetos. Observou-se, também, que muitos participantes tiveram dificuldade em posicionar a mesa de refeições no local pretendido (geralmente na cozinha), fator que frustrava a pessoa, levando a concluir que a dimensão da cozinha era insuficiente. Nestes casos, surgiram soluções 
como diminuir o tamanho da mesa, retirar alguma das cadeiras, e por fim, alguns optavam por retirar a mesa, incluindo apenas uma bancada para refeições.

Ainda, o desejo de possuir a mesa na cozinha revela a relação que as pessoas fazem da alimentação com o setor de serviço da casa, desejam reservar a sala como local limpo para recepção das visitas. Tal referência ultrapassa a questão do desejo e da prioridade mostrando um aspecto mais cultural. Segundo Lemos (1993) foi observado que na época colonialista a cozinha era ambiente privado, uma forma de assegurar que os visitantes não entrariam em contato com as mulheres, se limitando assim à sala.

Ao serem questionados sobre a preferência em ampliar um ambiente com a condição de ter que reduzir outro, vinte participantes escolheram deixar o projeto como estava. Ressaltou-se nas respostas que quase todos os ambientes são utilizados para variadas atividades, tendo sido apontado por vinte e duas pessoas que a possibilidade de alteração do mobiliário é importante. A motivação versava sobre o desejo de mudança da aparência do ambiente com objetivo de possuir "uma visão de casa nova".

A questão da ampliação da casa se apresentou nos resultados, apontando que ocorre mais desejo em compartimentar a casa do que necessariamente aumentar os ambientes, principalmente famílias que possuem de quatro a cinco pessoas ou como a pesquisa de Conceição (2015) aborda, famílias com filhos de gêneros diferentes querem possuir o terceiro dormitório.

Os entrevistados relataram no questionário que conseguiram entender o modelo digital, assim como a maquete, mesmo que alguns deles tenham citado sentir dificuldade na montagem do leiaute. Foi possível verificar que conseguiram incluir o mobiliário, quase sempre, de forma adequada.

A manipulação do mobiliário e das portas e janelas abriu oportunidade de experimentar as possíveis opções (Figura 11). Ocorreram diversas situações em que os participantes alteraram portas e janelas do local preferido depois de chegar à conclusão que não estavam adequadas. Neste caso, determinando uma prioridade, com base no resultado das experimentações. Uma entrevistada considerou que seria muito bom se todos pudessem ter a oportunidade de observar e manipular o projeto com o mobiliário antes de construir suas casas.

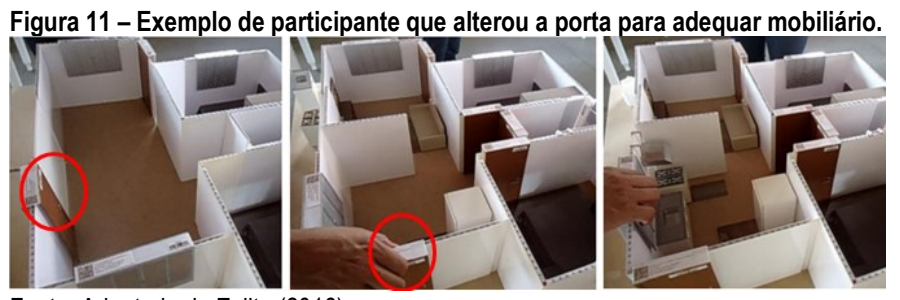

Fonte: Adaptado de Zalite (2016)
$\mathrm{Na}$ tentativa de identificar homogeneidades, observou-se que os participantes, com mais de 50 anos possuíam alguns aspectos similares como não possuir companheiro, pertencer a famílias de até três integrantes, desejar uma cozinha maior e também uma sacada no apartamento.

A indicação em possuir uma sacada foi citada por treze pessoas, as motivações apontaram fatores como espaço para lazer, convivência familiar e social, para animal de estimação, para colocar plantas e até para uso como extensão da área de serviço (secagem de roupas).

Quanto ao momento da simulação, os participantes demonstraram habilidade em organizar o leiaute, analisando o resultado de suas escolhas e logo em seguida optando por novas soluções e experimentações, caso desejassem, alterando as peças do mobiliário uma ou várias vezes, até se sentirem satisfeitos com o resultado final. A inclusão do mobiliário na maquete auxiliou o participante a reconhecer pontos de conflito nas circulações e espaços de usos dos equipamentos. Outro aspecto identificado foi a facilidade e rapidez de movimentar os elementos, permitindo experimentações e alterações no projeto realizadas pelos participantes.

Os entrevistados demonstraram que tinham a percepção espacial ampliada quando faziam correlações entre os ambientes por meio da analogia dos móveis e equipamentos demonstrados no modelo reduzido com a sua experiência pessoal de vida. Esse aspecto é ampliado quando a figura humana em escala reduzida é utilizada nos ambientes, auxiliando para diminuir as deformações de percepção decorrentes do aspecto reducionista do modelo.

\section{Conclusão}

A pesquisa demonstrou que a simulação de alternativas de leiaute com modelo físico tridimensional possui capacidade de auxiliar na identificação dos desejos e preferências das pessoas. O modelo físico permitiu que pessoas leigas pudessem alcançar um entendimento suficiente para interagir e aplicar soluções de projeto de forma prática.

O projeto da habitação ideal para cada pessoa é resultado de um desejo e de necessidades individuais. Acredita-se que apresentar opções limitadas, porém mais adequadas de projetos, onde o futuro morador pode realizar uma escolha, é uma forma de inclusão do usuário no processo do projeto. O poder de escolha proporciona um projeto mais adequado ao usuário, do que o fornecido atualmente de forma padronizada para todos os estratos de usuários. Dessa forma, nos planos institucionais, a tomada de decisão pelo usuário poderia dividir parte da responsabilidade com o futuro morador. A participação pode gerar maior satisfação da pessoa, aumentando a sua percepção de qualidade (IMAI, 2009). 
Outro aspecto sobre soluções projetuais de maior qualidade diz respeito à customização em massa, que adota a oferta de produtos que podem ser fabricados em série, mas com partes diferenciadas com objetivo de atender às novas demandas da sociedade, no que diz respeito à personalização dos objetos (AZUMA, 2016).

O sistema de coleta de informações também necessita de renovação, de organização e de constante modernização. A alta demanda por moradias dificulta a disponibilidade de oferta de produtos personalizados. No entanto, uma coleta inicial e mais sistematizada possibilita a identificação de grupos de perfis familiares por preferências. Por meio dos resultados, os gestores podem oferecer opções de projetos que atendam mais diretamente os grupos. De qualquer forma, a fase organizacional deve estar apoiada em um sistema tecnológico eficiente da construção das moradias para que o ciclo finalize adequadamente, resultando em habitações mais customizadas, que possam ser construídas em menor tempo sem gerar maiores custos (Figura 12).

Figura 12- Proposta de sistema para distribuição de habitações sociais com uso de dados dos usuários

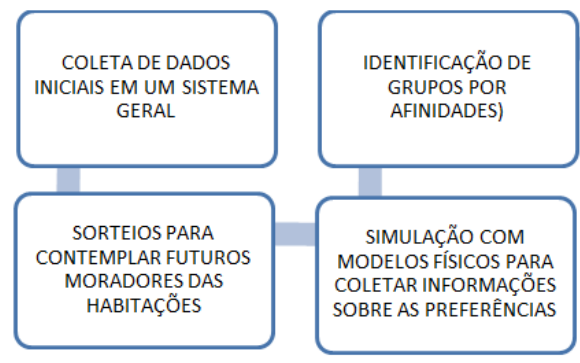

Fonte: Adaptado de Zalite (2016)

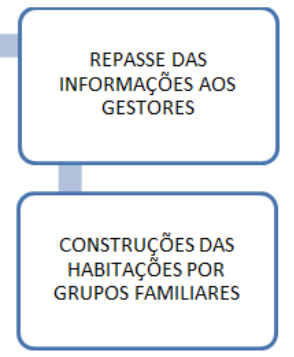

A pesquisa demonstrou que o tempo de interação dos futuros usuários com a maquete poder influenciar na quantidade e qualidade dos dados. Foi observado em estudo piloto, ocorrido anteriormente, (IMAI et al, 2015) que a simulação com duração de uma hora ocasionou cansaço em alguns entrevistados. Se por um lado, um tempo muito longo pode expor os participantes à fadiga, por outro, foi observado que reduzir a quantidade de questões para adequar ao tempo de trinta minutos na pesquisa descrita neste artigo, acarretou em dificuldade para os entrevistados em se sentirem satisfeitos ao finalizarem o leiaute, apresentando desejo de continuar desenvolvendo os aspectos do projeto. Assim, uma vez finalizado, tinham resistência em deixar o local, posicionando-se próximos à maquete, analisando e refletindo sobre novas soluções. Quando sugerido a continuação da simulação ao entrevistado, nesse caso sem o registro direto do pesquisador, abriu-se a possibilidade de proporcionar resultados mais espontâneos. Esse aspecto, ainda que não registrado de forma sistemática nessa pesquisa, pode ser investigado em pesquisas futuras.
A simulação com modelo físico possui aspectos que estimularam o seu uso pelo leigo e indicam sua contribuição na definição projetual. As ferramentas da preferência declarada e o modelo digital também demonstraram características complementares com o modelo físico que permite explorar uma variedade de aspectos e de abordagens entre os participantes (Quadro $1)$.

Quadro 1 - Aspectos identificados para as ferramentas utilizadas na pesquisa
\begin{tabular}{|c|c|}
\hline $\begin{array}{c}\text { PREFERÊNCIA DECLARADA - } \\
\text { MODELO DIGITAL }\end{array}$ & SIMULAÇÃO - MODELO FíSICO \\
\hline Rapidez na aplicação. & $\begin{array}{c}\text { Flexibilidade para fazer alterações } \\
\text { de forma rápida. }\end{array}$ \\
\hline $\begin{array}{c}\text { Capacidade de mobilidade do } \\
\text { pesquisador }\end{array}$ & $\begin{array}{c}\text { Compreensão das partes e do todo } \\
\text { - didática. }\end{array}$ \\
\hline $\begin{array}{c}\text { Fácil para abordar grande } \\
\text { número de pessoas. }\end{array}$ & $\begin{array}{c}\text { Capacidade de visualização e } \\
\text { discussão em grupos de pessoas }\end{array}$ \\
\hline $\begin{array}{c}\text { Boa Compreensão dos modelos } \\
\text { - didática }\end{array}$ & Possiblidade de manipulação. \\
\hline $\begin{array}{c}\text { Capacidade de abordar } \\
\text { variedade de temas, como cores, } \\
\text { coberturas, acabamento, outros. }\end{array}$ & $\begin{array}{c}\text { Capacidade de reflexão sobre a } \\
\text { decisão, ajuste e nova reflexão }\end{array}$ \\
\hline Fonte: Adaptado de Zalite (2016)
\end{tabular}

Os aspectos apontados por Voordt e Wegen (2013) para qualidade funcional dos projetos foram identificados por meio de modelo físico (Quadro 2). Ele favoreceu a relação das informações coletadas com os critérios de base da pesquisa, assim como o entendimento dos dados, de forma que as escolhas e prioridades subjetivas puderam ser adequadas aos aspectos funcionais.

Quadro 2 -Colaborações das ferramentas em relação aos critérios de base
\begin{tabular}{|c|c|}
\hline Requisitos & Maquete Física \\
\hline FLEXIBILIDADE & $\begin{array}{c}\text { Proporciona a manipulação do mobiliário e a } \\
\text { reflexão das decisões. Alterações imediatas na } \\
\text { tentativa de encontrar novas soluções desejadas. }\end{array}$ \\
\hline SEGURANÇA & $\begin{array}{c}\text { Facilitou a reflexão e identificação do melhor local } \\
\text { para as aberturas nos ambientes. A elaboração } \\
\text { do leiaute permitiu identificar pontos de conflito na } \\
\text { circulação e uso do mobiliário. }\end{array}$ \\
\hline $\begin{array}{c}\text { ORIENTAÇÃO } \\
\text { ESPACIAL }\end{array}$ & $\begin{array}{c}\text { Permitiu a verificação estética das escolhas da } \\
\text { localização das portas e das janelas. Para muitos } \\
\text { a aparência da fachada foi item decisive. }\end{array}$ \\
\hline PRIVACIDADE & $\begin{array}{c}\text { Possibilitou alterações e viabilizou incluir e retirar } \\
\text { paredes e janelas quando não estavam em } \\
\text { acordo com as prioridades. Alguns preferem tirar } \\
\text { portas da fachada para impedir que seja possivel } \\
\text { observar o fundo da casa. }\end{array}$ \\
\hline SAÚDE E BEM- \\
ESTAR & $\begin{array}{c}\text { Auxiliou a concretizar as situações cotidianas, se } \\
\text { preocuparam com ventilação, porém observaram- } \\
\text { se maiores preocupações com conflitos entre } \\
\text { janela e mobiliário e qual seria vista dos } \\
\text { ambientes. }\end{array}$ \\
\hline
\end{tabular}

Fonte: Adaptado de Zalite (2016)

A identificação das preferências dos usuários observadas com auxílio de modelos tridimensionais demonstrou colaborar na identificação das prioridades dos usuários de HIS nos aspectos funcionais propostos pela pesquisa. A abordagem dos entrevistados por meio de um instrumento 
mais próximo ao universo de conhecimento deles possibilita uma analogia com o ambiente real em seu aspecto tridimensional, podendo envolver o usuário, facilitando a obtenção de dados sobre aspectos coletivos e de personalização individual. A simulação com o modelo demonstrou eficácia na comunicação do projeto para pessoas leigas ao aproximar os envolvidos das decisões sobre o projeto da moradia e auxiliar os futuros moradores a fazerem escolhas mais conscientes.

\section{Referências}

ABIKO, A. K.; ORNSTEIN, S. W. (Org.). Inserção urbana e avaliação pós-ocupação (APO) da habitação de interesse social. São Paulo: FAUUSP, 2002. (Coletânea Habitare, v. 1).

\section{AZUMA, M. H.. Customização em massa de projeto de Habitação de Interesse Social por meio de modelos físicos} paramétricos. 2016. Tese (Doutorado em Arquitetura e Urbanismo) - Universidade de São Paulo - IAU - USP, São Carlos.

BECHTEL, Robert. Advances in POE Methods: An Overview. In: Preiser, W.F. E. Building Evaluation. ed. Springer-Verlag US, 1989. p 199-206.

BARROS, A. A. B.; COUTO, M. E. G. Sobre os hábitos de morar e a estética da casa: alguns estudos de caso em Maceió, AL. In: PROJETAR: Ensino, Pesquisa e Prática, 6., 2013. Salvador. Anais... Salvador: UFBA, 2013. Disponível em: $<$ http://projedata.grupoprojetar.ufrn.br/dspace/handle/123456789/1871>. Acesso em: 10 dez. 2015.

BLANK-FREITAS, A. C.; AÑAÑA, E. S.; SCHRAMM F. K. Avaliação pós-ocupação de habitações de intersse social e a captura de requisitos do cliente final. In: SIMPÓSIO BRASILEIRO DE QUALIDADE DO PROJETO NO AMBIENTE CONSTRUÍDO, 3., ENCONTRO DE TECNOLOGIA DE INFORMAÇÃO E COMUNICAÇÃO NA CONSTRUÇÃO, 6. 2013, Campinas. Anais... Campinas: ANTAC, 2013. Disponível em:

<http://wp.ufpel.edu.br/naurb/files/2015/09/sbpq2013_aline.pdf>. Acesso em: 20 nov. 2015.

CELANI, G. et al. Imprimindo ideias: viabilização do uso de impressoras para maquetes arquitetônicas. In: INTERNATIONAL CONFERENCE ON GRAPHICS ENGINEERING FOR ARTS AND DESIGN (GRAPHICA), 7., 2007, Curitiba.

Proceedings... Curitiba: UFPR, 2007. Disponível em: $<$ https://sites.google.com/a/tematico.arq.br/principal/Home/publicacoes $>$. Acesso em: 27 nov. 2015.

CELANI, G. et al. O processo de produção de uma maquete com técnicas de prototipagem digital. In: SIMPÓSIO NACIONAL DE GEOMETRIA DESCRITIVA E DESENHO TÉCNICO (GRAPHICA), 19., Bauru. Anais... Bauru: UNESP, 2009. Disponível em: <http://www.fec.unicamp.br/ lapac/papers/celani-et-al2009b.pdf>. Acesso em: 27 nov. 2015.

CONCEIÇÃO, P.A. Método para classificação de famílias visando a adoção de customização em massa por segmento de habitação de interesse social. 2015. 166 f.Dissertação (Mestrado em Arquitetura e Urbanismo) - Programa Associado de Pósgraduação de Arquitetura, UEL/UEM, Londrina. Disponível em:

http://www.bibliotecadigital.uel.br/document/?view=vtls000202251

DEL RIO, V.; DUARTE, C. R.; RHEINGANTZ, P. A. Projeto do lugar: colaboração entre arquitetura, psicologia e urbanismo. Rio de Janeiro: Contra capa/PROARQ, 2002.

ELALI, G. V. M. A. Processo projetual e estresse ambiental: explorando aspectos que podem influenciar na relação usuário - ambiente. In: ORNSTEIN, S.; FABRÍCO, M. M. (Org.). Qualidade no projeto de edifícios. São Carlos: Rima, 2010.

ELALI, G. V. M. A.; PINHEIRO, J. Q. Analisando a experiência do habitar: algumas estratégias metodológicas. In: VILLA, S. B.; ORNSTEIN, S. W. (Org.). Qualidade ambiental na habitação: avaliação pós-ocupação. São Paulo: Oficina de Textos, 2013.

FLORIO, W.; TAGLIARI, A. Fabricação digital de maquetes físicas: tangibilidade no processo de projeto em Arquitetura. Exacta, São Paulo, 2011, v. 9, n. 1, p. 125-136. Disponível em: <http://www.redalyc.org/articulo.oa?id=81018619010>. Acesso em: 1 jun. 2015. 
GÜNTHER, H.; ELALI, G. A.; PINHEIRO, J. Q. A abordagem multimétodos em Estudos Pessoa-Ambiente: características, definições e implicações. Brasília: Instituto de Psicologia, UNB, 2004. (Textos de Psicologia Ambiental, n. 23).

GÜNTHER, H.; ELALI, G. A.; PINHEIRO, J. Q. Multimétodos. In: CAVALCANTE, S.; ELALI, G. V. M. A. (Org.). Temas básicos em psicologia ambiental. Petrópolis: Vozes, 2011. p. 239-250.

IMAI, C. O processo projetual e a percepção dos usuários: o uso de modelos tridimensionais físicos na elaboração de projetos de habitação social. Ambiente Construído, Porto Alegre, v. 9, n. 2, p. 105-118, abr./jun. 2009. Disponível em: http://www.seer.ufrgs.br/index.php/ambienteconstruido/article/view/7410

IMAI, Cesar et al. O MODELO TRIDIMENSIONAL FÍSICO COMO INSTRUMENTO DE SIMULAÇÃO NA HABITAÇÃO SOCIAL. Gestão \& Tecnologia de Projetos, Brasil, v. 10, n. 2, p. 7-20, nov. 2015. ISSN 1981-1543. doi:http://dx.doi.org/10.11606/gtp.v10i2.101782.

KOWALTOWSKI, D. C. C. K. et al. Quality of life and sustainability issues as seen by the population of low-income housing in the region of Campinas, Brazil. Habitat International, v. 30,n. 4, p. 1100-1114, dec. 2006. ISSN 0197-3975 https://doi.org/10.1016/j.habitatint.2006.04.003

LEMOS, C. Transformações do espaço habitacional ocorridas na arquitetura brasileira do século XIX . Anais do Museu Paulista: História e Cultura Material, São Paulo, v. 1, n. 1, p. 95-106, 1993. Disponível em:

$<$ https://www.revistas.usp.br/anaismp/article/view/5277>. Acesso em: 11 ago. 2017.

PALLASMAA, J. Os olhos da pele. Porto Alegre: BOOKMAN, 2011.

ORNSTEIN S, FABRÍCIO M.M.; MELHADO S. B. Conceitos de qualidade no projeto de edifícios . In: ORNSTEIN, S.; FABRÍCO, M. M. (Org.). Qualidade no projeto de edifícios. São Carlos: Rima, 2010.

PALERMO, C. Avaliação da qualidade no projeto de HIS: uma parceria com a Cohab/SC. In: VILLA, S. B.; ORNSTEIN, S. W. (Org.). Qualidade ambiental na habitação: avaliação pós-ocupação. São Paulo: Oficina de Textos, 2013. p. $209-233$.

PINA, S. A. M.; BORGES FILHO, F.; MARANGONI, R. F. Maquetes e modelos como estímula à criatividade no projeto arquitetônico. In: Kowaltowski D. C.C.K.; Moreira, D. C.; Petreche, J. R.D.; Fabríco, M. M.(orgs.) O processo do projeto em arquitetura: da teoria à tecnologia. São Paulo: Oficina de Textos, 2013.p. 109 - 123.

PUPO, R., A.; CELANI, M. G. C. Prototipagem rápida e fabricação digital na arquitetura: fundamentação e formação. In: KOWALTOWSKI, D. C. C. K. et al. (Org.). O processo de projeto em arquitetura: da teoria à tecnologia. São Paulo: Oficina de Textos, 2011.

REIS, A. T.; LAY, M. C. D. Avaliação estética de empreendimentos habitacionais de interesse social. In: VILLA, S. B.; ORNSTEIN, S. W. (Org.). Qualidade ambiental na habitação: avaliação pós-ocupação. São Paulo: Oficina de Textos, 2013.

ROZESTRATEN, A. S. Estudo sobre a história dos modelos arquitetônicos: origens e características das primeiras maquetes de arquiteto. 2003. Dissertação (Mestrado em Estruturas Ambientais Urbanas) - Faculdade de Arquitetura e Urbanismo, Universidade de São Paulo, São Paulo.

SILVA, R. D.; SILVA, B. F. O programa habitacional minha casa minha vida: uma avaliação através do caso do Conjunto Albino Meneguetti em Maringá - PR. set. 2012. Disponível em:

$<$ http://revistas.javeriana.edu.co/index.php/cvyu/article/view/5916>. Acesso em: 27 nov. 2015.

SALGADO, M. S. Arquitetura centrada no usuário ou no cliente? Uma reflexão sobre a qualidade do projeto. In: ORNSTEIN, S.; FABRÍCO, M. M. (Org.). Qualidade no projeto de edifícios. São Carlos: Rima, 2010.

SANOFF, H. Visual research methods in design. New York: Van Nostrand Reinhold, 1991.

SPRECKELMEYER, K. Environmental Programming, In: BECHTEL, R. et al. Environmental and behavioral research. (Ed.). New York: Van Nostrand Reinhold, 1987. p. 247-269. 
TRAMONTANO, M. Habitações, metrópoles e modos de vida: por uma reflexão sobre a habitação contemporâneo. São Paulo: Instituto dos Arquitetos do Brasil/ Museu da Casa Brasileira, 1997. Texto premiado, $3^{\circ}$ Prêmio Jovens Arquitetos.

VILLA, S. B. et al. A ineficiência de um modelo de morar mínimo: análise pós-ocupacional em habitação de interesse social em Uberlândia-MG. Observatorium: Revista Eletrônica de Geografia, Uberlândia, v. 5, n. 14, p. 121-147, out. 2013

VOORDT, V. D. T. J. M.; WEGEN, W. H. B.R. Arquitetura sob o olhar do usuário. São Paulo: Oficina de Textos, 2013.

WANG, D.; GROAT, L. Architecture reseach methods. New York: J. Wiley Sons, 2002.

ZALITE, M. G. de A.. A simulação com modelo físico como modo de identificação das prioridades declaradas dos usuários no projeto da habitação de interesse social .2016. 157 f. Dissertação (Mestrado em Arquitetura e Urbanismo) - Universidade Estadual de Londrina - UEL, Londrina, 2006. Disponível em: http://www.bibliotecadigital.uel.br/document/?code=vtls000207942

${ }^{1}$ Marcela Gomes de Albuquerque Zalite

Arquiteta e Urbanista. Mestre. Centro Universitário Unicesumar. Av. Guedner, 1610 - Jardim Aclimação, Maringá, Paraná, Brasil, CEP 87050-900

${ }^{2}$ César Imai

Arquiteto e Urbanista. Doutor. Universidade Estadual de Londrina - CTU / DAU, Rodovia Celso Garcia Cid / PR 445 KM380, Londrina, Paraná, Brasil, CEP 86.057-970 